\title{
Erratum to: Aquaculture genomics, genetics and breeding in the United States: current status, challenges, and priorities for future research
}

The Aquaculture Genomics, Genetics and Breeding Workshop, Hisham Abdelrahman', Mohamed ElHady², Acacia Alcivar-Warren ${ }^{3}$, Standish Allen ${ }^{4}$, Rafet Al-Tobasei ${ }^{5}$, Lisui Bao ${ }^{1}$, Ben Beck ${ }^{6}$, Harvey Blackburn", Brian Bosworth ${ }^{8}$, John Buchanan ${ }^{9}$, Jesse Chappell ${ }^{1}$, William Daniels ${ }^{1}$, Sheng Dong ${ }^{1}$, Rex Dunham ${ }^{1}$, Evan Durland ${ }^{10}$, Ahmed Elaswad', Marta Gomez-Chiarri ${ }^{11}$, Kamal Gosh', Ximing Guo ${ }^{12}$, Perry Hackett ${ }^{13}$, Terry Hanson', Dennis Hedgecock ${ }^{14}$, Tiffany Howard ${ }^{1}$, Leigh Holland ${ }^{1}$, Molly Jackson ${ }^{15}$, Yulin Jin ${ }^{1}$, Karim Khalil ${ }^{1}$, Thomas Kocher ${ }^{16}$, Tim Leeds ${ }^{17}$, Ning Li ${ }^{1}$, Lauren Lindsey ${ }^{1}$, Shikai Liu', Zhanjiang Liu ${ }^{1 *}, K^{1}$ le Martin ${ }^{18}$, Romi Novriadi ${ }^{1}$, Ramjie Odin ${ }^{1}$, Yniv Palti ${ }^{17}$, Eric Peatman ${ }^{1}$, Dina Proestou ${ }^{19}$, Guyu Qin ${ }^{1}$, Benjamin Reading ${ }^{20}$, Caird Rexroad ${ }^{21}$, Steven Roberts ${ }^{22}$, Mohamed Salem ${ }^{5}$, Andrew Severin ${ }^{23}$, Huitong Shi ${ }^{1}$, Craig Shoemaker ${ }^{6}$, Sheila Stiles ${ }^{24}$, Suxu Tan ${ }^{1}$, Kathy F. J. Tang ${ }^{25}$, Wilawan Thongda', Terrence Tiersch ${ }^{26}$, Joseph Tomasso ${ }^{1}$, Wendy Tri Prabowo ${ }^{1}$, Roger Vallejo ${ }^{17}$, Hein van der Steen ${ }^{27}$, Khoi Vo ${ }^{1}$, Geoff Waldbieser ${ }^{8}$, Hanping Wang ${ }^{28}$, Xiaozhu Wang ${ }^{1}$, Jianhai Xiang ${ }^{29}$, Yujia Yang ${ }^{1}$, Roger Yant ${ }^{30}$, Zihao Yuan', Qifan Zeng ${ }^{1}$ and Tao Zhou'

\section{Erratum}

In the version of this article that was originally published [1] there was an error with the author name "Karim Khalil" as it was incorrectly put as "Karim Kahlil". The original article was corrected.

\begin{abstract}
Author details
${ }^{1}$ School of Fisheries, Aquaculture and Aquatic Sciences, Auburn University, Auburn, AL 36849, USA. ²Department of Biological Sciences, Auburn University, Auburn, AL 36849, USA. ${ }^{3}$ Environmental Genomics Inc., P. O. Box 196, Southborough, MA 01772-1801, USA. ${ }^{4}$ Aquaculture Genetics \& Breeding Technology Center, Virginia Institute of Marine Science, Gloucester Point, VA 23062, USA. ${ }^{5}$ Department of Biology, Middle Tennessee State University, Murfreesboro, TN 37132, USA. ${ }^{6}$ Aquatic Animal Health Research Unit, USDA-ARS, 990 Wire Road, Auburn, AL 36832, USA. 'USDA-ARS-NL Wheat \& Corn Collections at a Glance GRP, National Animal Germplasm Program, 1111 S. Mason St., Fort Collins CO 80521-4500, USA. ${ }^{8}$ USDA-ARS/CGRU, 141 Experimental Station Road, Stoneville, MS 38701, USA. ${ }^{9}$ Center for Aquaculture Technologies, 8395 Camino Santa Fe, Suite E, San Diego, CA 92121, USA. ${ }^{10}$ Department of Fisheries and Wildlife, Oregon State University, Corvallis, OR 97331, USA. " ${ }^{11}$ Department of Fisheries, Animal \& Veterinary Science, 134 Woodward Hall, 9 East Alumni Avenue, Kingston, RI 02881, USA. ${ }^{12}$ Haskin Shellfish Research Laboratory, Department of Marine and Coastal Sciences, Rutgers University, 6959 Miller Avenue, Port Norris, NJ 08349, USA. ${ }^{13}$ Department of Genetics, Cell Biology and Development, 5-108 MCB, 420 Washington Avenue SE, Minneapolis, MN 55455, USA. ${ }^{14}$ Department of Biological Sciences, University of Southern California, Los Angeles, CA
\end{abstract}

\footnotetext{
* Correspondence: liuzhan@auburn.edu

'School of Fisheries, Aquaculture and Aquatic Sciences, Auburn University, Auburn, AL 36849, USA
}

90089-0371, USA. ${ }^{15}$ Taylor Shellfish Farms, 130 SE Lynch RD, Shelton, WA 98584, USA. ${ }^{16}$ Department of Biology, University of Maryland, 2132 Biosciences Research Building, College Park, MD 20742, USA. ${ }^{17}$ National Center for Cool and Cold Water Aquaculture, Agricultural Research Service, United States Department of Agriculture, Kearneysville, WV 25430, USA. ${ }^{18}$ Troutlodge, 27090 Us Highway 12, Naches, WA 98937, USA. ${ }^{19}$ USDA ARS NEA NCWMAC Shellfish Genetics at the University Rhode Island, 469 CBLS, 120 Flagg Road, Kingston, RI 02881, USA. ${ }^{20}$ Department of Applied Ecology, North Carolina State University, Raleigh, NC 27695-7617, USA. ${ }^{21}$ USDA ARS Office of National Programs, George Washington Carver Center Room 4-2106, 5601 Sunnyside Avenue, Beltsville, MD 20705, USA. ${ }^{22}$ School of Aquatic and Fishery Sciences, University of Washington, Seattle, WA 98105, USA. ${ }^{23}$ Genome Informatics Facility, Office of Biotechnology, lowa State University, Ames, IA 50011, USA. ${ }^{24}$ USDOC/NOAA, National Marine Fisheries, NEFSC, Milford Laboratory, Milford, Connectcut 06460, USA. ${ }^{25}$ School of Animal and Comparative Biomedical Sciences, University of Arizona, Tucson, AZ 85721, USA. ${ }^{26}$ Aquatic Germplasm and Genetic Resources Center, School of Renewable Natural Resources, Louisiana State University Agricultural Center, Baton Rouge, LA 70820, USA. ${ }^{27}$ Stonebridge breeding Ltd, Gate House, Abbotswood, Evesham WR11 4NS, UK. ${ }^{28}$ Aquaculture Genetics and Breeding Laboratory, The Ohio State University South Centers, Piketon, $\mathrm{OH}$ 45661, USA. ${ }^{29}$ Key Laboratory of Experimental Marine Biology, Institute of Oceanology, Chinese Academy of Sciences, Qingdao 266071, China. ${ }^{30}$ Hybrid Catfish Company, 1233 Montgomery Drive, Inverness, MS 38753, USA.

Received: 8 March 2017 Accepted: 8 March 2017

Published online: 16 March 2017

\section{Reference}

1. The Aquaculture Genomics, Genetics and Breeding Workshop, Abdelrahman H, ElHady M, Alcivar-Warren A, Allen S, et al. Aquaculture genomics, genetics and breeding in the United States: current status, challenges, and priorities for future research. BMC Genomics. 2017;18:191. 